\title{
Decrease of physical activity level in adolescents with limb fractures: an accelerometry-based activity monitor study
}

\author{
Dimitri Ceroni ${ }^{1,4^{*}}$, Xavier Martin ${ }^{1}$, Cécile Delhumeau ${ }^{2}$ and Nathalie Farpour-Lambert ${ }^{3}$
}

\begin{abstract}
Background: Immobilization and associated periods of inactivity can cause osteopenia, the physiological response of the bone to disuse. Mechanical loading plays an essential role in maintaining bone integrity. Skeletal fractures represent one cause of reduction of the physical activity (PA) level in adolescents. The purpose of this study was to quantify the reduction of PA in adolescents with limb fractures during the cast immobilization period compared with healthy controls.

Methods: Two hundred twenty adolescents were divided into three groups: those with upper limb fractures (50 cases); lower limb fractures (50 cases); and healthy cases (120 cases). Patients and their healthy peers were matched for gender, age, and seasonal assessment of PA. PA level was assessed during cast immobilization by accelerometer. Time spent in PA in each of the different intensity levels - sedentary, light, moderate, and vigorous was determined for each participant and expressed in minutes and as a percentage of total valid time.

Results: Reduction in PA during cast immobilization was statistically significant in patients with limb fractures compared to healthy controls. The total PA count (total number of counts/min) was significantly lower in those with upper and lower limb fractures $(-30.1 \%$ and $-62.4 \%$, respectively) compared with healthy controls $(p<0.0001$ and $p=0.0003$, respectively). Time spent in moderate-to-vigorous PA by patients with upper and lower limb injuries decreased by $36.9 \%(p=0.0003)$ and $76.6 \%(p<0.0001)$, respectively, and vigorous PA was reduced by $41.4 \%(p=0.0008)$ and $84.4 \%(p<0.0001)$, respectively.

Conclusions: PA measured by accelerometer is a useful and valid tool to assess the decrease of PA level in adolescents with limb fractures. As cast immobilization and reduced PA are known to induce bone mineral loss, this study provides important information to quantify the decrease of skeletal loading in this patient population. The observed reduction of high intensity skeletal loading due to the decrease in vigorous PA may explain osteopenia due to disuse, and these data should be kept in mind by trauma practitioners to avoid any unnecessary prolongation of the cast immobilization period.
\end{abstract}

\section{Background}

Bone mineral mass acquired during adolescence is considered as a major determinant of adult bone health [1]. Although genetic factors have a strong influence on peak bone mass, environmental factors, such as physical activity (PA), also contribute $[2,3]$. Exercise exerts a positive effect on bone growth, particularly if the activity has been initiated before puberty or in the early pubertal

\footnotetext{
* Correspondence: dimitri.ceroni@hcuge.ch

${ }^{1}$ Pediatric Orthopedic Unit, University of Geneva Hospitals and University of Geneva Faculty of Medicine, Geneva, Switzerland

Full list of author information is available at the end of the article
}

period [4-6]. The skeleton appears to be most responsive to mechanical stress during Tanner stages II-IV and corresponds to the two-year window that has been identified as the period of bone mineral accrual during puberty $[7,8]$. Bone mineral mass is higher in physically active children than in those who are mildly active [9], and higher in children who participate in activities that generate high impact forces than in those who practise activities with lower impact forces [10-12]. Studies have shown that high-intensity forces, especially when imposed during early childhood, produce greater gains in bone mass than low- to moderate-intensity forces

C Biomed Central

(C) 2011 Ceroni et al; licensee BioMed Central Ltd. This is an Open Access article distributed under the terms of the Creative Commons Attribution License (http://creativecommons.org/licenses/by/2.0), which permits unrestricted use, distribution, and reproduction in any medium, provided the original work is properly cited. 
[13-18]. Based on this evidence, it is now recommended that physical activity for children include activities generating relatively high ground-reaction forces, such as jumping, skipping, running, and possibly strengthening exercises [5].

It is recognized also that immobilization and associated periods of inactivity can cause osteopenia [19-21], the physiological response of the bone to disuse. Mechanical loading plays an essential role in maintaining bone integrity. Mechanisms underlying bone loss in response to disuse are not yet completely understood, even if it is recognized that they are due to increased bone resorption and corresponding reduced bone formation. In adolescents, loss of bone mineral mass usually occurs during phases of reduced PA, such as cast immobilization [22]. To the best of our knowledge, the measurement of PA levels by accelerometry has not been investigated in adolescents who sustain limb fractures and have to wear a cast for several weeks. The objective of our study was to quantify the reduction of PA levels during cast immobilization in this patient population.

\section{Methods}

\section{Subjects}

One hundred adolescents with a first episode of limb fracture (50 lower limb fractures; 50 upper limb fractures) and a control group of 120 healthy cases were recruited for inclusion in the study through an advertisement for visitors to the Children's Hospital of the University of Geneva Hospitals, Geneva, Switzerland. Exclusion criteria for both injured adolescents and healthy controls were: prior history of bone fractures; chronic disease; congenital or acquired bone disease; any condition limiting physical activity; and hospitalization for more than 2 weeks in the previous 12 months.

Adolescents with limb fractures were treated as inpatients and required general anesthetic for the treatment of their fracture. Those with lower limb fractures received a bent-knee long-leg cast and were instructed to follow a strict zero weight-bearing directive during the initial healing phase. After 3 to 6 weeks, the initial immobilization device was removed and a below-the-knee walking cast was worn until definitive bone healing. All adolescents with upper limb fractures were immoblized into a long-arm cast during the initial healing phase, followed by a forearm cast until definitive bone healing. All study participants and their parents provided written consent and the protocol was approved by the institutional ethics committee (protocol \# 04-057, ped 04-002).

\section{Anthropometric measurements}

Standing height was assessed in bare or stocking feet to the nearest $1 \mathrm{~mm}$ using a precision mechanical stadiometer (Holtain Ltd, Dyfed, UK). Weight was measured to the nearest $0.1 \mathrm{~kg}$ using a mechanical calibrated beam scale (Seca ${ }^{\circledR}$, Reinach, Switzerland). Body mass index (BMI) was calculated as weight $(\mathrm{kg}) /$ height squared $\left(\mathrm{m}^{2}\right)$.

\section{Physical activity measurement}

Physical activity was measured during cast immobilization and data were collected from the first day following hospital discharge. Recordings of PA began on a Monday, Tuesday or Wednesday to ensure measurement of at least two weekend days. Objective measurements of PA were obtained using an uniaxial accelerometer (Acti$\operatorname{graph}^{\circledR} 7164$, MTI, Fort Walton Beach, FL, USA). The monitor was set on a 1 min cycle and the sum was stored in the memory at the end of each run and the numerical integrator reset. The monitor was attached above the iliac crest of the right hip with an elastic belt and adjustable buckle, and was oriented vertically in the same direction. The accelerometer was programmed to start recording at $8 \mathrm{am}$ on the first day of measurement and participants were asked to wear it continuously, including during the night, for 10 days. Data were collected during all seasons.

\section{PA data interpretation}

Data reduction was based on criteria applied in previous publications [3,23-26]. Only periods between 8 am and $9 \mathrm{pm}$ were analysed. Zero activity periods of $20 \mathrm{~min}$ or longer were interpreted as being due to unworn accelerometers and were removed from the activity totals [27]. Participants who did not record more than $600 \mathrm{~min} / \mathrm{d}$ of activity [3,23-26] for at least 5 days were excluded from further analysis [28]. Data were expressed as total activity counts per registered time (counts/min) to generate an average range of PA. We used the cut-offs of intensity levels described by Ekelund where sedentary behaviour was defined as less than 500 counts/min, light PA from 500 to 1999 counts/min, moderate PA from 2000 to 2999 counts/min, and vigorous PA as $>3000$ counts/min [29]. Time spent at each PA intensity level was determined for all participants as a percentage of total valid time.

\section{Statistical methods}

Data are expressed as mean \pm SD. A paired Student's $t$ test with an alpha threshold of 5\% was used to analyze the variability of matching characteristics (age and gender) for cases and healthy controls. A Shapiro Wilk test with an alpha threshold of $5 \%$ was used to test the normality of PA variables. As these variables did not have a normal distribution, a paired Wilcoxon test with an alpha threshold of $5 \%$ was used to assess differences of PA levels between cases and healthy controls. Data analyses were performed using STATA 9.2 (StataCorp LP, Texas, USA). 


\section{Results}

Fourteen adolescents with lower limb fractures, 13 with upper limb fractures, and 25 control subjects were excluded either for failing to reach at least 5 days of measurement or instrument malfunction. Thirty-six adolescents with lower limb fractures, 37 with upper limb fractures, and 95 healthy controls were included in the study. Type of fracture, treatment, and cast immobilization duration are shown in Table 1. Patients with limb fractures were paired with healthy controls according to gender, age ( \pm 0.5 years), and seasonal assessment, as the latter may have an impact on the PA level (less sporting activities during the winter months). Thirty-five patients with upper limb fractures were able to be matched with 35 healthy controls; pairing was possible in 34 cases for the lower limb fracture group. Age, physical characteristics, and PA levels of those with fractures and healthy controls are presented in Tables 2 and 3. There was no statistical difference between groups for age, height, weight, BMI, or daily duration of PA monitoring. A statistical difference for the mean number of valid monitored days was observed between patients with lower limb fractures and healthy controls $(9.1 \pm 1.8$ vs $8.2 \pm 2$, respectively; $p=0.028)$. As expected, cases with limb fractures showed notable reductions in PA levels and spent more time in sedentary activities. The total PA count (number of counts/ min) was significantly lower in those with upper and lower limb fractures $(-30.1 \%$ and $-62.4 \%$, respectively) compared with healthy controls. When considering time spent in moderate-to-vigorous PA, a substantial decrease was observed in the upper $(-36.9 \%)$ and lower limb $(-76.6 \%)$ fracture groups compared to matched healthy controls. Finally, the decrease in vigorous PA was highly significant for both injured groups $(-41.4 \%$ and $-84.4 \%$ for cases with upper and lower limb fractures, respectively) (Figure 1).

\section{Discussion}

Skeletal fractures represent one cause of reduction of the PA level in adolescents. To the best of our knowledge, this is the first study to report PA measures in a representative sample of this population with upper and lower limb fractures. As expected, we observed a significant reduction of PA levels among injured subjects during cast immobilization, especially those with lower limb fractures. Using total activity measurement, subjects with upper or lower limb fractures were considerably less active $(-30.1 \%$ and $-62.4 \%$, respectively) than healthy fracture-free controls. This was even more marked for time spent in activities of moderate-to- vigorous intensity. For both groups of healthy control subjects, the average time spent in moderate-to-vigorous intensity activity was $59.4 \mathrm{~min}$ and $66.7 \mathrm{~min}$ daily, whereas it was $42.1 \mathrm{~min}$ and $13.9 \mathrm{~min}$, respectively, for adolescents with upper and lower limb fractures.

International guidelines recommend that school-age children should participate daily in at least $60 \mathrm{~min}$ of moderate-to-vigorous intensity activity as this level has been shown to prevent weight gain, premature development of cardiovascular diseases and type 2 diabetes, and to increase bone mineral mass [30]. PA reduction in

Table 1 Type of Lesion, Treatment, and Cast Immobilization Duration of Adolescents with Upper and Lower Limb Fractures

\begin{tabular}{|c|c|c|c|}
\hline \multicolumn{2}{|l|}{ Upper $\operatorname{limb}(n=50)$} & \multicolumn{2}{|l|}{ Lower $\operatorname{limb}(n=50)$} \\
\hline \multicolumn{4}{|l|}{ Type of lesion } \\
\hline Physeal fractures of the wrist & 18 & Physeal fractures of the ankle & 38 \\
\hline $\begin{array}{l}\text { Distal metaphyseal fractures of the radius \& cubitus of the } \\
\text { wrist }\end{array}$ & 29 & Distal metaphyseal fractures of tibia and fibula & 4 \\
\hline \multirow[t]{3}{*}{ Forearm shaft fractures } & 3 & Leg fractures & 4 \\
\hline & & Medial malleolus fractures & 2 \\
\hline & & Lateral malleolus fractures & 2 \\
\hline \multicolumn{4}{|l|}{ Treatment } \\
\hline Closed reduction and cast immobilization & 45 & Closed reduction and cast immobilization & 33 \\
\hline \multirow[t]{2}{*}{$\begin{array}{l}\text { Stabilization of closed reduction by per-cutaneous wires/ } \\
\text { screws \& cast immobilization }\end{array}$} & 5 & $\begin{array}{l}\text { Stabilization of closed reduction by per-cutaneous wires/ } \\
\text { screws \& cast immobilization }\end{array}$ & 7 \\
\hline & & ORIF and cast immobilization & 10 \\
\hline \multicolumn{4}{|l|}{ Cast immobilization duration } \\
\hline Long-arm cast immobilization & $\begin{array}{l}26.5+/- \\
5.8 \text { days }\end{array}$ & Non-weight-bearing above the knee cast immobilization & $\begin{array}{l}27.4+/- \\
10.3 \text { days }\end{array}$ \\
\hline Forearm cast immobilization & $\begin{array}{l}23.3+/- \\
10.4 \text { days }\end{array}$ & Weight-bearing cast & $\begin{array}{l}26.4+/-8.8 \\
\text { days }\end{array}$ \\
\hline
\end{tabular}

The results are expressed as " $\mathrm{n}$ " or mean $+/-$ SD. 
Table 2 Characteristics and Physical Activity Measures of Adolescents with Upper Limb Fractures during Cast Immobilization vs Healthy Controls

\begin{tabular}{|c|c|c|c|}
\hline & $\begin{array}{l}\text { Injured adolescents } \\
(\mathrm{n}=35)\end{array}$ & $\begin{array}{l}\text { Healthy controls } \\
(\mathrm{n}=35)\end{array}$ & $p$ value \\
\hline Age (yr) & $12.6 \pm 1.7$ & $12.6 \pm 1.8$ & 0.5244 \\
\hline Height $(\mathrm{cm})$ & $157.7 \pm 13.4$ & $157.7 \pm 11.8$ & 0.9989 \\
\hline Weight (kg) & $47.3 \pm 12.1$ & $46.3 \pm 11.4$ & 0.4253 \\
\hline BMI $\left(\mathrm{kg} / \mathrm{m}^{2}\right)$ & $18.7 \pm 2.4$ & $18.4 \pm 2.5$ & 0.2610 \\
\hline Number of valid monitored days (days) & $8.7+/-2.4$ & $8.1+/-2.4$ & 0.2044 \\
\hline Daily duration of physical activity monitoring (min) & $752.1 \pm 26.8$ & $740.9 \pm 37.4$ & 0.3177 \\
\hline $\begin{array}{l}\text { Total activity } \\
\text { (counts/min.day) }\end{array}$ & $417.5 \pm 179.1$ & $597.1 \pm 211.4$ & $0.0003^{*}$ \\
\hline $\begin{array}{l}\text { Time spent in sedentary activity (min/day) } \\
\text { (\% of total daily wearing time) }\end{array}$ & $\begin{array}{l}598.2+/-54.7 \\
79.6\end{array}$ & $\begin{array}{l}540.4+/-64.4 \\
72.9\end{array}$ & $0.0001^{*}$ \\
\hline $\begin{array}{l}\text { Time spent in light activity (min/day) } \\
\text { (\% of total daily wearing time) }\end{array}$ & $\begin{array}{l}111.8+/-41.1 \\
14.9\end{array}$ & $\begin{array}{l}136.5+/-40.1 \\
18.4\end{array}$ & $0.0072^{*}$ \\
\hline $\begin{array}{l}\text { Time spent in moderate (min/day) } \\
\text { (\% of total daily wearing time) }\end{array}$ & $\begin{array}{l}20.7+/-8.4 \\
2.7\end{array}$ & $\begin{array}{l}30.2+/-12 \\
4.1\end{array}$ & $0.0003^{*}$ \\
\hline $\begin{array}{l}\text { Time spent in vigorous activity (min/day) } \\
\text { (\% of total daily wearing time) }\end{array}$ & $\begin{array}{l}21.4+/-15.2 \\
2.8\end{array}$ & $\begin{array}{l}36.5+/-18.9 \\
4.9\end{array}$ & $0.0008^{*}$ \\
\hline
\end{tabular}

The results are expressed as mean \pm SD.

*: statistically significant difference [please always place at foot of table].

adolescents with fractures results in a decrease in energy expenditure and our clinical experience has shown that this decrease during the cast immobilization period may be the starting point of weight gain for children and adolescents [31].

An examination of time spent in vigorous PA is even more relevant as bone health is related to ground reaction forces [32]. It is well known that an intensification of high impact and weight-bearing exercises has direct and positive consequences in relation to bone mass. Recent studies focus on the theory that high-intensity forces, especially if imposed rapidly, produce greater gains in bone mineral mass than low-to-moderate intensity forces [13,16-18]. Our study investigated specifically the time spent in vigorous PA, which reflects highintensity forces beneficial to skeletal health, and

Table 3 Characteristics and Physical Activity Measures of Adolescents with Lower Limb Fractures during Cast Immobilization vs Healthy Controls

\begin{tabular}{|c|c|c|c|}
\hline & $\begin{array}{l}\text { Injured adolescents } \\
(n=34)\end{array}$ & $\begin{array}{l}\text { Healthy controls } \\
(\mathrm{n}=34)\end{array}$ & $p$ value \\
\hline Age (yr) & $13.6 \pm 1.6$ & $13.3 \pm 1.6$ & 0.2312 \\
\hline Height (cm) & $161.9 \pm 11.1$ & $162 \pm 12.9$ & 0.9501 \\
\hline Weight (kg) & $52.1 \pm 11.8$ & $51.8 \pm 11.8$ & 0.8128 \\
\hline $\mathrm{BMI}\left(\mathrm{kg} / \mathrm{m}^{2}\right)$ & $19.7 \pm 2.5$ & $19.5 \pm 2.5$ & 0.2614 \\
\hline Number of valid monitored days (days) & $9.1+/-1.8$ & $8.2+/-2$ & $0.0276^{*}$ \\
\hline Daily duration of physical activity monitoring (min) & $746.7 \pm 22.9$ & $749.3 \pm 33.3$ & 0.8241 \\
\hline $\begin{array}{l}\text { Total activity } \\
\text { (counts/min.day) }\end{array}$ & $200.9 \pm 92.3$ & $534.5 \pm 207.3$ & $<0.0001^{*}$ \\
\hline $\begin{array}{l}\text { Time spent in sedentary activity (min/day) } \\
\text { (\% of total daily wearing time) }\end{array}$ & $\begin{array}{l}664.4+/-40.9 \\
89\end{array}$ & $\begin{array}{l}564.3+/-64.4 \\
75.3\end{array}$ & $<0.0001^{*}$ \\
\hline $\begin{array}{l}\text { Time spent in light activity (min/day) } \\
\text { (\% of total daily wearing time) }\end{array}$ & $\begin{array}{l}68.4+/-26.4 \\
9.2\end{array}$ & $\begin{array}{l}125.7+/-40.1 \\
16.8\end{array}$ & $<0.0001^{*}$ \\
\hline $\begin{array}{l}\text { Time spent in moderate (min/day) } \\
\text { (\% of total daily wearing time) }\end{array}$ & $\begin{array}{l}8.9+/-7.2 \\
1.2\end{array}$ & $\begin{array}{l}27.5+/-11.4 \\
3.7\end{array}$ & $<0.0001^{*}$ \\
\hline $\begin{array}{l}\text { Time spent in vigorous activity (min/day) } \\
\text { (\% of total daily wearing time) }\end{array}$ & $\begin{array}{l}5+/-6.8 \\
0.6\end{array}$ & $\begin{array}{l}31.8+/-18 \\
4.2\end{array}$ & $<0.0001^{*}$ \\
\hline
\end{tabular}

The results are expressed as mean \pm SD.

*: statistically significant difference (please always place at foot of table). 


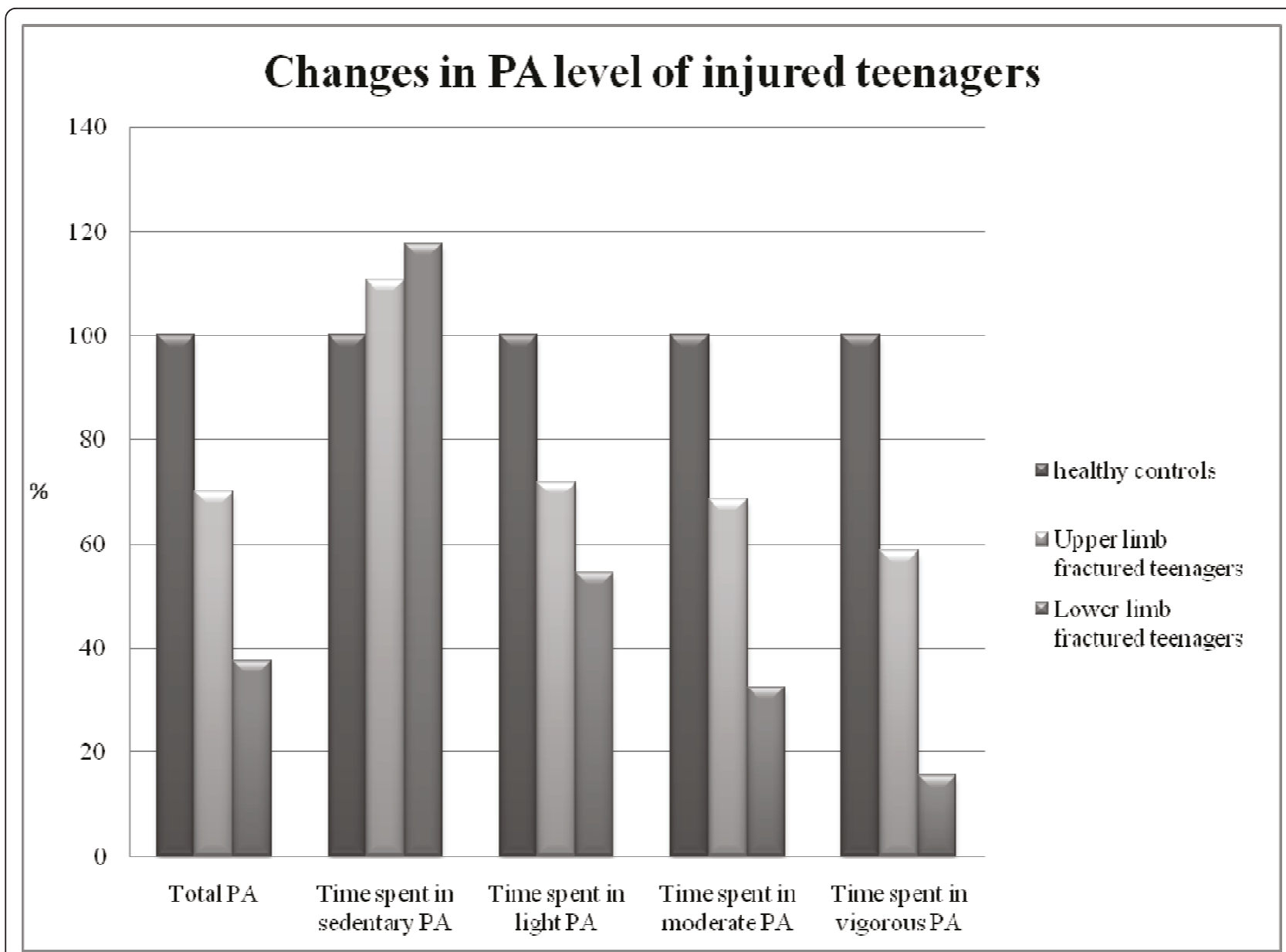

Figure 1 Physical activity levels of injured teenagers expressed as percentages of healthy teenager's results. In this graph PA levels of healthy teenagers are $100 \%$. All the differences between injured teenagers and the healthy controls were highly sigificant (For the $p \_v a l u e s, ~ c f$ the tables 2 \& 3).

demonstrated a $41.4 \%$ and $84.4 \%$ decrease, respectively, in adolescents with upper and lower limb fractures. The significant reduction in high-intensity forces applied to the skeleton may provide also a valid explanation for disuse osteopenia [33]. Restoration of bone mineral mass may occur upon reaching pubertal maturity [33,34] and, above all, normal activity [35]. Nevertheless, there are currently no reported studies on the recovery of PA levels following limb fractures in children and adolescents.

The results of this study constitute a starting point for new investigations. The relationship between PA decrease and bone mineral loss in youth with fractures remains to be established in a prospective study. There are also some limitations to be considered when interpreting the findings of our study. First, our recruitment was relatively heterogeneous, in particular with regard to the practice of sport. Even if we are unable to completely rule out the possibility of selection bias, there is no clear reason to believe that adolescents with markedly different PA profiles would have chosen to participate in the study. Second, there are activities during which accelerometers have to be removed (e.g., swimming) or do not accurately measure the intensity level (e.g., cycling). These "unmonitored" activities may result in an underestimation of PA in healthy controls. Nevertheless, Trost et al reported that children's self-reported periods of "unmonitored" activity added to the registered accelerometer data led to no significant changes in calculated PA levels [36]. Third, to obtain 10 days of measurement recording, activity counts were averaged using a 1-min epoch to ensure that the accelerometer memory capacity was not exceeded. However, this method underestimates vigorous PA as such activity is rarely sustained for longer than $1 \mathrm{~min}$ [25]. Although previous studies have demonstrated that vigorous PA may be substantially underestimated [37], this is unlikely to be of importance in this study as we can hypothesize that it will be the same for the different groups. 


\section{Conclusions}

PA measured by accelerometer is a useful and valid tool to assess the decrease of PA levels in adolescents with limb fractures. As cast immobilization and reduced PA are known to induce bone mineral loss, this study provides important information to quantify the decrease of skeletal loading in adolescents with limb fractures. The significant reduction in time spent in vigorous PA, which reflects high-intensity forces beneficial to skeletal health, provides a valid explanation for disuse osteopenia. These data are important and should be kept in mind by trauma practitioners to avoid an unnecessary prolongation of the cast immobilization period. This study gives an outline of the decrease of PA due to a sedentary behaviour and emphasizes the role of physical activity. Further research is needed to establish the relationship between the PA level and bone mineral acquisition during cast immobilization and after bone healing.

\section{Acknowledgements}

We thank the participants and their families for their willing cooperation in this study. We acknowledge Magali Oehrli and the staff of the pediatric orthopedic unit of the Department of Child and Adolescent, University of Geneva Hospitals, for their technical assistance. We acknowledge also Rosemary Sudan for editorial assistance. This work was supported by grants from the Swiss National Science Foundation (SNSF \#405340-104611), and the funding source did not have any Funding sources: Supported by grants from the Swiss National Science Foundation (SNSF \#405340-104611) role in the investigation.

\section{Author details \\ ${ }^{1}$ Pediatric Orthopedic Unit, University of Geneva Hospitals and University of Geneva Faculty of Medicine, Geneva, Switzerland. ${ }^{2}$ Clinical Epidemiology Service, University of Geneva Hospitals and University of Geneva Faculty of Medicine, Geneva, Switzerland. ${ }^{3}$ Exercise Medicine, Pediatric Cardiology Unit, University of Geneva Hospitals and University of Geneva Faculty of Medicine, Geneva, Switzerland. ${ }^{4}$ Department of Child and Adolescent, University of Geneva Hospitals and University of Geneva Faculty of Medicine, Geneva, Switzerland.}

\section{Authors' contributions}

DC: participated in the design of the study, conceived and coordinated the study, collected and treated the patients, performed the CSA analysis, and drafted the manuscript. XM: conceived the study, participated in its coordination, collected the data, and performed the statistical analysis. CD: performed the statistical analysis and drafted the manuscript. NFL: participated in the design and conception of the study, and drafted the manuscript. All authors read and approved the final version of the manuscript.

\section{Competing interests}

The authors declare that they have no competing interests.

Received: 7 November 2010 Accepted: 4 May 2011

Published: 4 May 2011

\section{References}

1. Saggese G, Baroncelli Gl, Bertelloni S: Osteoporosis in children and adolescents: diagnosis, risk factors, and prevention. J Pediatr Endocrinol Metab 2001, 14(7):833-59.

2. Barr SI, McKay HA: Nutrition, exercise, and bone status in youth. Int J Sport Nutr 1998, 8(2):124-42.

3. Craig $C L$, Marshall $A L$, Sjostrom M, Bauman $A E$, Booth $M L$, Ainsworth $B E$, Pratt M, Ekelund U, Yngve A, Sallis JF, Oja P: International physical activity questionnaire: 12-country reliability and validity. Med Sci Sports Exerc 2003, 35(8):1381-95.

4. Bailey DA, Martin AD, McKay HA, Whiting S, Mirwald R: Calcium accretion in girls and boys during puberty: a longitudinal analysis. J Bone Miner Res 2000, 15(11):2245-50.

5. Kohrt WM, Bloomfield SA, Little KD, Nelson ME, Yingling VR: American College of Sports Medicine Position Stand: physical activity and bone health. Med Sci Sports Exerc 2004, 36(11):1985-96.

6. Heinonen A, Sievanen $H$, Kannus P, Oja P, Pasanen M, Vuori I: High-impact exercise and bones of growing girls: a 9-month controlled trial. Osteoporos Int 2000, 11(12):1010-7.

7. Bailey DA: The Saskatchewan Pediatric Bone Mineral Accrual Study: bone mineral acquisition during the growing years. Int J Sports Med 1997, 18(Suppl 3):S191-4.

8. Theintz G, Buchs B, Rizzoli R, Slosman D, Clavien H, Sizonenko PC, Bonjour JP: Longitudinal monitoring of bone mass accumulation in healthy adolescents: evidence for a marked reduction after 16 years of age at the levels of lumbar spine and femoral neck in female subjects. $J$ Clin Endocrinol Metab 1992, 75(4):1060-5.

9. Slemenda CW, Miller JZ, Hui SL, Reister TK, Johnston CC Jr: Role of physical activity in the development of skeletal mass in children. J Bone Miner Res 1991, 6(11):1227-33.

10. Cassell C, Benedict M, Specker B: Bone mineral density in elite 7- to 9-yrold female gymnasts and swimmers. Med Sci Sports Exerc 1996, 28(10):1243-6.

11. Courteix D, Lespessailles E, Peres SL, Obert P, Germain P, Benhamou CL: Effect of physical training on bone mineral density in prepubertal girls: a comparative study between impact-loading and non-impact-loading sports. Osteoporos Int 1998, 8(2):152-8.

12. Khan KM, Bennell KL, Hopper JL, Flicker L, Nowson CA, Sherwin AJ, Crichton KJ, Harcourt PR, Wark JD: Self-reported ballet classes undertaken at age 10-12 years and hip bone mineral density in later life. Osteoporos Int 1998, 8(2):165-73

13. Fuchs RK, Snow CM: Gains in hip bone mass from high-impact training are maintained: a randomized controlled trial in children. J Pediatr 2002 141(3):357-62.

14. MacKelvie KJ, Khan KM, Petit MA, Janssen PA, McKay HA: A school-based exercise intervention elicits substantial bone health benefits: a 2-year randomized controlled trial in girls. Pediatrics 2003, 112(6 Pt 1):e447.

15. MacKelvie KJ, McKay HA, Petit MA, Moran O, Khan KM: Bone mineral response to a 7-month randomized controlled, school-based jumping intervention in 121 prepubertal boys: associations with ethnicity and body mass index. J Bone Miner Res 2002, 17(5):834-44.

16. McKay HA, Petit MA, Schutz RW, Prior JC, Barr SI, Khan KM: Augmented trochanteric bone mineral density after modified physical education classes: a randomized school-based exercise intervention study in prepubescent and early pubescent children. J Pediatr 2000, 136(2):156-62.

17. Morris FL, Naughton GA, Gibbs JL, Carlson JS, Wark JD: Prospective tenmonth exercise intervention in premenarcheal girls: positive effects on bone and lean mass. J Bone Miner Res 1997, 12(9):1453-62.

18. Petit MA, McKay HA, MacKelvie KJ, Heinonen A, Khan KM, Beck TJ: A randomized school-based jumping intervention confers site and maturity-specific benefits on bone structural properties in girls: a hip structural analysis study. J Bone Miner Res 2002, 17(3):363-72

19. Vico L, Collet P, Guignandon A, Lafage-Proust MH, Thomas T, Rehaillia M, Alexandre C: Effects of long-term microgravity exposure on cancellous and cortical weight-bearing bones of cosmonauts. Lancet 2000, 355(9215):1607-11.

20. Frey-Rindova P, de Bruin ED, Stussi E, Dambacher MA, Dietz V: Bone mineral density in upper and lower extremities during 12 months after spinal cord injury measured by peripheral quantitative computed tomography. Spinal Cord 2000, 38(1):26-32.

21. Leblanc AD, Schneider VS, Evans HJ, Engelbretson DA, Krebs JM: Bone mineral loss and recovery after 17 weeks of bed rest. $J$ Bone Miner Res 1990, 5(8):843-50.

22. Szalay EA, Harriman D, Eastlund B, Mercer D: Quantifying postoperative bone loss in children. Journal of Pediatric Orthopedics 2008, 28:320-3.

23. Brage S, Wedderkopp N, Ekelund U, Franks PW, Wareham NJ, Andersen LB Froberg K: Objectively measured physical activity correlates with indices of insulin resistance in Danish children. The European Youth Heart Study (EYHS). Int J Obes Relat Metab Disord 2004, 28(11):1503-8. 
24. Ekelund U, Aman J, Westerterp K: Is the ArteACC index a valid indicator of free-living physical activity in adolescents? Obes Res 2003, 11(6):793-801.

25. Riddoch CJ, Bo Andersen L, Wedderkopp N, Harro M, Klasson-Heggebo L, Sardinha LB, Cooper AR, Ekelund U: Physical activity levels and patterns of 9- and 15-yr-old European children. Med Sci Sports Exerc 2004, 36(1):86-92.

26. Schmidt MD, Freedson PS, Chasan-Taber L: Estimating physical activity using the CSA accelerometer and a physical activity log. Med Sci Sports Exerc 2003, 35(9):1605-11.

27. Treuth MS, Sherwood NE, Butte NF, McClanahan B, Obarzanek E, Zhou A, Ayers C, Adolph A, Jordan J, Jacobs DR, Rochon J: Validity and reliability of activity measures in African-American girls for GEMS. Med Sci Sports Exerc 2003, 35(3):532-9.

28. Hayden-Wade HA, Coleman KJ, Sallis JF, Armstrong C: Validation of the telephone and in-person interview versions of the 7-day PAR. Med Sci Sports Exerc 2003, 35(5):801-9.

29. Ekelund U, Sardinha LB, Anderssen SA, Harro M, Franks PW, Brage S, Cooper AR, Andersen LB, Riddoch C, Froberg K: Associations between objectively assessed physical activity and indicators of body fatness in 9- to 10-y-old European children: a population-based study from 4 distinct regions in Europe (the European Youth Heart Study). Am J Clin Nutr 2004, 80(3):584-90.

30. Strong WB, Malina RM, Blimkie CJR, Daniels SR, Dishman RK, Gutin B, Hergenroeder AC, Must A, Nixon PA, Pivarnik JM, Rowland T, Trost S, Trudeau F: Evidence Based Physical Activity for School-age Youth. The Journal of Pediatrics 2005, 146(6):732-737.

31. Jiménez-Pavón D, Kelly J, Reilly JJ: Associations between objectively measured habitual physical activity and adiposity in children and adolescents: Systematic review. Int J Pediatr Obes 2010, 5(1):3-18.

32. Freedson P, Pober D, Janz KF: Calibration of accelerometer output for children. Med Sci Sports Exerc 2005, 37(11 Suppl):S523-30.

33. Ferrari SL, Chevalley T, Bonjour JP, Rizzoli R: Childhood fractures are associated with decreased bone mass gain during puberty: an early marker of persistent bone fragility? J Bone Miner Res 2006, 21(4):501-7.

34. Jones IE, Williams SM, Dow N, Goulding A: How many children remain fracture-free during growth? a longitudinal study of children and adolescents participating in the Dunedin Multidisciplinary Health and Development Study. Osteoporos Int 2002, 13(12):990-5.

35. Giangregorio L, Blimkie CJ: Skeletal adaptations to alterations in weightbearing activity: a comparison of models of disuse osteoporosis. Sports Med 2002, 32(7):459-76.

36. Trost SG, Pate RR, Sallis JF, Freedson PS, Taylor WC, Dowda M, Sirard J: Age and gender differences in objectively measured physical activity in youth. Med Sci Sports Exerc 2002, 34(2):350-5.

37. Nilsson AEU, Yngve A, Sjöström M: Assessing physical activity among children with accelerometers using different time sampling intervals and placements. Pediatr Exerc Sci 2002, 14:87-96.

Pre-publication history

The pre-publication history for this paper can be accessed here: http://www.biomedcentral.com/1471-2474/12/87/prepub

\section{doi:10.1186/1471-2474-12-87}

Cite this article as: Ceroni et al: Decrease of physical activity level in adolescents with limb fractures: an accelerometry-based activity monitor study. BMC Musculoskeletal Disorders 2011 12:87.

\section{Submit your next manuscript to BioMed Central and take full advantage of:}

- Convenient online submission

- Thorough peer review

- No space constraints or color figure charges

- Immediate publication on acceptance

- Inclusion in PubMed, CAS, Scopus and Google Scholar

- Research which is freely available for redistribution

Submit your manuscript at www.biomedcentral.com/submit 